\title{
The possible involvement of protein synthesis in the injection of PL-1 phage genome into its host, Lactobacillus casei
}

\author{
Kenji Watanabe, ${ }^{*}$ Mitsuhiro Shirabe, Yukihiko NaKashima and Yukari KaKita \\ Microbiology Laboratory, Faculty of Pharmaceutical Sciences, Fukuoka University, Fukuoka 814-01, Japan
}

(Received 21 January 1991; revised 23 July 1991; accepted 31 July 1991)

\begin{abstract}
The process of genome DNA injection, after adsorption, by phage PL-1 into host cells of Lactobacillus casei was monitored by using the electron microscope. Injection of DNA was inhibited by the protein-synthesis inhibitors chloramphenicol and erythromycin at concentrations where the colony-forming ability of cells not infected by phage was unaffected. The results suggest that protein synthesis may be involved in some way in the process of genome injection.
\end{abstract}

\section{Introduction}

Information on the initial stages of infection by bacteriophages with a long non-contractile tail, especially on the process of genome injection after adsorption, is much less extensive than that for phages with a contractile tail sheath, such as T-even coliphages. These contractile tail sheaths play an important role in the injection of the phage genome into the host cell (Goldberg, 1980).

We have been investigating the mechanism of genome injection by phage PL-1, which has an icosahedral head with a long non-contractile tail, into the host Lactobacillus casei by determining (i) the amounts of ${ }^{32} \mathrm{P}$-labelled phage not sheared from the phage-adsorbed cells by blender treatment (Hershey \& Chase, 1952), (ii) the number of plaque-forming phage-cell complexes after blending (Watanabe et al., 1979), (iii) the hostkilling ability of the phages (Watanabe \& Takesue, 1972), and (iv) the number of ghost particles with empty heads observed by electron microscopy (Watanabe et al., 1987). These studies have demonstrated that the process of genome injection is dependent on $\mathrm{Ca}^{2+}$ and a high intracellular concentration of high-energy compounds such as ATP.

In the present paper, we have examined by electron microscopy the effects of some protein-synthesis inhibitors on the process of genome injection.

\section{Methods}

Phage and bacterial host. Phage PL-1 and its host Lactobacillus casei ATCC 27092 have been described previously (Watanabe et al., 1970, 1982).
Phage genome injection. Cells were infected with phages in MR
medium (pH 6.0) (Murata et al., 1969) at $37^{\circ} \mathrm{C}$ during the exponential
growth phase $\left(\mathrm{OD}_{600}=0.35\right.$, about $\left.2.5 \times 10^{8} \mathrm{c} . \mathrm{f} . \mathrm{u} . \mathrm{ml}^{-1}\right)$ at a multi-
plicity of infection of about 100 . When the effects of protein-synthesis
inhibitors were tested, they were added to the cell suspensions either
before, at the same time or after the cells were infected with phages.
The extent of PL-1 DNA injection was determined from the increase
with time in the number of ghost particles with empty heads among
phages already absorbed to the cells. Chloramphenicol was purchased
from Sankyo and erythromycin was from Sigma.

Electron microscopy. After fixing the phage-cell complexes with $2 \%$ (v/v) glutaraldehyde at $0{ }^{\circ} \mathrm{C}$ for $90 \mathrm{~min}$, and washing by centrifugation, the pellets were suspended in TMB-Ca $(50 \mathrm{mM}-\mathrm{Tris} / \mathrm{maleate}$ buffer, $\left.\mathrm{pH} 6.0,+10 \mathrm{~mm}-\mathrm{CaCl}_{2}\right)$ and negatively stained with $2 \%(\mathrm{w} / \mathrm{v})$ uranyl acetate for electron microscopy. The electron micrographs were taken with a JEOL-100C electron microscope at $80 \mathrm{kV}$.

\section{Results and Discussion}

Most of the input phages were adsorbed to the cells almost instantly and in a tail-first orientation, irrespective of the presence of antibiotics. After appropriate times, samples of the infected cell suspensions were removed and fixed with glutaraldehyde for electron microscopy. The proportion of ghost particles having an empty head (which were easily distinguished from intact phages with tightly packed DNA) among the total phage particles adsorbed to a cell [ghost/(intact + ghost) $\times 100$ ] was determined for 20-30 separate cells from each sample. Each cell was usually observed to adsorb on average about 40 phage particles.

Fig. 1 shows the relationship between the concentrations of protein-synthesis inhibitors and the extent of PL-1 DNA injection, which was derived from the number of ghost particles observed $80 \mathrm{~min}$ after 


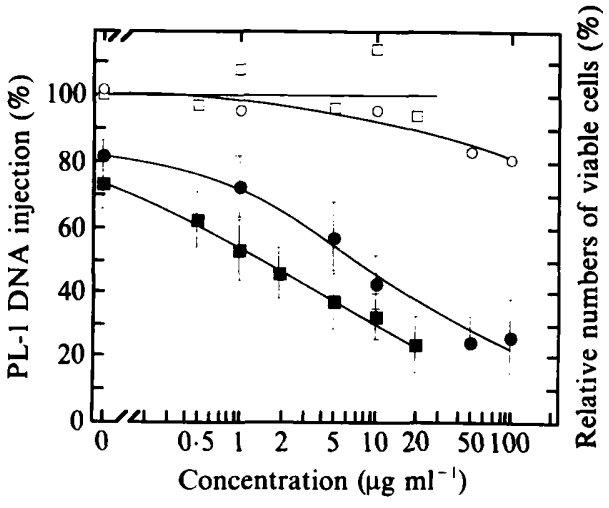

Fig. 1

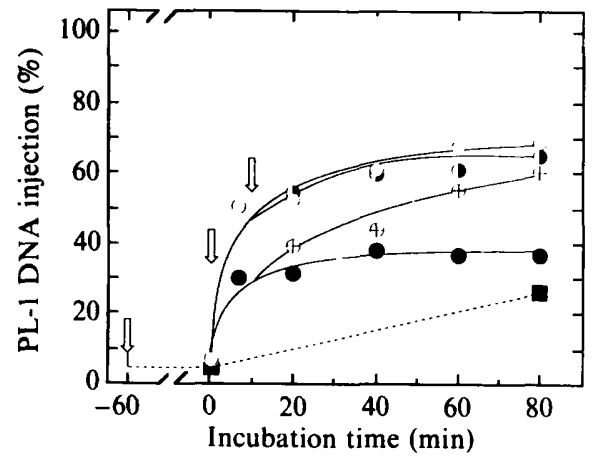

Fig. 2

Fig. 1. Effect of the concentrations of protein-synthesis inhibitors on the extent of PL-1 DNA injection into L. casei. Cells, which had been pretreated with various concentrations of chloramphenicol $(\bullet, 0)$ or erythromycin $(\square, \square)$ for 60 min, were mixed with phages at a multiplicity of infection of about 100 , and incubated at $37^{\circ} \mathrm{C}$ for $80 \mathrm{~min}$ in MR medium (pH 6.0). $\bullet, \square$, Percentage of PL-1 DNA injected. $O, \square$, Relative numbers of viable cells. Vertical bars show the standard deviation of the mean.

Fig. 2. Effect of chloramphenicol on the extent of PL-1 DNA injection. Chloramphenicol $\left(2.0 \mathrm{mg} \mathrm{ml}^{-1}\right)$ was added to the incubation mixture at $-60(\square), 0(\bullet)$ and $10 \mathrm{~min}(\Theta)$, and removed from the inhibited mixture at $10 \mathrm{~min}(\oplus)$, as indicated by the arrows. $O$, Control without chloramphenicol. The standard deviation was, on average, about $10 \%$.

infection. In a control experiment without the addition of antibiotics, the extent of PL-1 DNA injection increased with time up to a maximum of about $80 \%$, and was usually completed within $60 \mathrm{~min}$. By contrast, when the host cells were pre-incubated with the drugs for $60 \mathrm{~min}$ at $37^{\circ} \mathrm{C}$ prior to infection, the extent of DNA injection decreased with increasing drug concentration. The concentrations of drug required to decrease the number of ghost phages by half were about $7 \mu \mathrm{g} \mathrm{ml}^{-1}$ for chloramphenicol and $1.5 \mu \mathrm{g} \mathrm{ml}^{-1}$ for erythromycin. Cell suspensions treated for $60 \mathrm{~min}$ with these antibiotics, but not subsequently infected with phages, showed no reduction in viability when diluted and plated onto MR agar plates. This confirmed that under the conditions used, these antibiotics have no bactericidal effect and protein synthesis resumes in antibiotic-treated cells.

At various times after the infection of cells with phages, chloramphenicol was added to a final concentration of $2.0 \mathrm{mg} \mathrm{ml}^{-1}$, and, at intervals, the phage-cell complexes were observed by electron microscopy. Fig. 2 shows the changes with time in the number of ghost phages, i.e. the extent of PL-1 DNA injection, with or without chloramphenicol. When chloramphenicol was added immediately after mixing the cells with phage suspension, the extent of DNA injection was similar to that seen when chloramphenicol was added to the cells $60 \mathrm{~min}$ before infection. However, when chloramphenicol was added to the cells $10 \mathrm{~min}$ after the phages (which had already started to inject their DNA), injection was not affected. Thus the inhibitory effect of chloramphenicol on DNA injection was observed only when added before DNA injection. These results suggest that protein synthesis in the host cells may be required only for initiation of PL-1 DNA injection and not injection itself, although there is the alternative possibility that the process possibly driven by transcription, as suggested for other systems, may require protein synthesis.

Then, 10 min after cells had been infected with phages in the presence of chloramphenicol, the stabilized cellphage complexes were freed from chloramphenicol by centrifugation and resuspension in fresh MR medium. Incubation was continued. The resuspended cells underwent infection at the same rate as control cells which had not been exposed to chloramphenicol (Fig. 2).

Transfer of the genomes of phages lacking a contractile tail sheath from the phage head to the host cytoplasm has been reported (Roessner et al., 1983; Filali Maltouf \& Lebedan, 1983; Letellier \& Labedan, 1985; Sabelnikov, 1989) to be independent of membrane potential (Mitchell, 1976). The synthesis of one or more proteins in the newly infected cells has been demonstrated to be required for infection by phage T5 (Lanni, 1965). It was reported for phage $\mathrm{T} 7$ that transfer of the first $60 \%$ of the DNA was tightly coupled with its transcription by the host RNA polymerase (Zavriev \& Vorob'ev, 1984), although the influence of proteinsynthesis inhibitors was not investigated. Since, in our experiments, both chloramphenicol and erythromycin inhibited the injection of PL-1 DNA, it is likely that proteins synthesized during the early stages of infection and prior to complete DNA transfer itself are required for transfer of DNA from phage PL-1 to cells of $L$. casei. Further investigations on the participation of protein 
synthesis in this process are now being carried out, since chloramphenicol has been reported to inhibit a wide range of biochemical processes besides protein synthesis.

\section{References}

Filali Maltouf, A. \& Labedan, B. (1983). Host cell metabolic energy is not required for injection of bacteriophage T5 DNA. Journal of Bacteriology 153, 124-133.

GOLDBERG, E. (1980). Bacteriophage nucleic acid penetration. In Receptors and Recognition, series B, vol. 7, part 1, pp. 115-141. Edited by L. L. Randall \& L. Philipson. London \& New York: Chapman and Hall.

HeRshey, A. D. \& Chase, M. (1952). Independent functions of viral protein and nucleic acid in growth of bacteriophage. Journal of General Physiology 36, 39-56.

LANNI, Y. T. (1965). DNA transfer from phage T5 to host cells: Dependence on intercurrent protein synthesis. Proceedings of the National Academy of Sciences of the United States of America 53, 969-973.

LETELLIER, L. \& LABEDAN, B. (1985). Release of respiratory control in Escherichia coli after bacteriophage adsorption : process independent of DNA injection. Journal of Bacteriology 161, 179-182.

MrTCHELl, P. (1976). Vectorial chemistry and the molecular mechanics of chemiosmotic coupling: power transmission by proticity. Biochemical Society Transactions 4, 399-430.
Murata, A., Soeda, E. \& Saruno, R. (1969). Factors influencing plaque formation by bacteriophages of Lactobacillus acidophilus. Nippon Nogeikagaku Kaishi 43, 311-316.

Roessner, C. A., Struck, D. K. \& IhLER, G. M. (1983). Injection of DNA into liposomes by bacteriophage $\lambda$. Journal of Biological Chemistry 258, 643-648.

SABELNIKov, A. G. (1989). DNA transfer through cell membranes in bacteria. Bioelectrochemistry and Bioenergetics 22, 271-288.

WatanaBe, K. \& TAKesue, S. (1972). The requirement for calcium in infection with Lactobacillus phage. Journal of General Virology 17, 19-30.

Watanabe, K., Takesue, S., Jin-NaI, K. \& Yoshikawa, T. (1970), Bacteriophage active against the lactic acid beverage-producing bacterium Lactobacillus casei. Applied Microbiology 20, 409-415.

Watanabe, K., Takesue, S. \& IshibashI, K. (1979). Adenosine triphosphate content in Lactobacillus casei and the blender-resistant phage-cell complex-forming ability of cells on infection with PL-1 phage. Journal of General Virology 42, 27-36.

Watanabe, K., Takesue, S., Ishibashi, K., Iwamoto, T. \& Kondo, J. (1982). Fine structure of PL-1 phage active against Lactobacillus casei. Journal of General and Applied Microbiology 28, 1-6.

Watanabe, K., Fukuzaki, T., Hayashida, M. \& Nakashima, Y. (1987). Electron microscopic study of the process of DNA ejection from the head of PL-1, a Lactobacillus casei phage. Journal of General Virology 68, 569-572.

ZAVRIEV, S. K. \& VoROB'EV, S. M. (1984). Evidence for the coupling of T7 DNA injection with its transcription during infection. FEBS Letters 165, 31-34. 